\title{
Psychological Problems Resulting from Parent-to-Adolescent Renal Transplantation
}

\author{
Monica N. Starkman, M.D. \\ Assistant Professor of Psychiatry, Chief, Adult Service Consultation-Liaison Program, Department of Psychiatry, \\ University of Michigan Medical Center, Ann Arbor, Michigan
}

\begin{abstract}
This paper deals with the ways in which the psychological responses of renal transplant donors and recipients interfere with the developmental tasks of adolescence. The characteristic responses of donors and recipients in general are briefly reviewed. The special problems of the adolescent who has received a transplant from a parent are considered. Interference with the separation-individuation process is discussed. Also considered is the difficulty posed to the development of sexual identity. Excerpts from brief therapy are presented that illustrate the characteristic psychological conflicts described.
\end{abstract}

Although there is an extensive literature regarding psycholugical aspects of renal transplantation, only a small number of publications address psychological features concerning adolescents in particular $(1-5)$. This paper focuses on the special difficulties that parent-to-adolescent transplantation poses to the developmental tasks of adolescence. Excerpts from the brief therapy of one patient are presented that illustrate the psychodynamics and the need for brief psychotherapeutic intervention when the characteristic conflicts interfere with psychological growth and maturation.

\section{Interference with the Separation-Individuation Process}

The separation-individuation process depends on an interplay between parent and child. Both must be able to tolerate the child's independent decision making and risk taking, the devaluation of the parent, and the expression of some hostility towards the parent. Both must be comfortable with the shifting needs of the child for closeness and for distance. When a parent-to-child renal transplant has occurred, it is precisely these capacities that are weakened by the psychological responses evoked by the procedure.

The transplant donor characteristically develops feelings of investment in the recipient, and a sense of possessiveness is commonly present (6). The donor also experiences unconscious hostility toward the person responsible for the loss of a vital body part (7). While the hostility of the parental donor may on occasion be expressed openly, guilt and reaction formation may occur, which leads to overconcern and overprotectiveness of the adolescent. This can further augment the overprotectiveness that stems from parental fear that loss or damage will occur to the kidney being "housed" by the recipient.

The donor may experience anticipatory anxiety related to his or her awareness that the recipient (and also the donor's body part) has a reprieve from death that probably is only temporary. This may lead to sudden withdrawals of affection and a distancing from the child (8). For this reason, it is not only the adolescent who is experiencing the typical adolescent instability of alternating wishes for closeness and for distance; the parent, as a transplant donor, also experiences similar shifts of feeling.

The transplant recipient tends to identify with the somatic and psychological characteristics of the donor (9). The recipient may experience an increased need for closeness and feelings of union with the donor $(9,10)$. How difficult it is for an adolescent recipient to separate from a parent whose introject is a physical, not just a psychological reality. The fact that the parent has in actuality 
been a source of new life may strengthen the fantasy of the parent as omnipotent life-giver and increase the wish for a strong dependent bond. The development of a sense of loyalty to the parent may further decrease autonomy in terms of the child's ability to form his or her own judgments.

Recipients also experience themselves as destructive, possibly having limited or curtailed another's life by appropriating their vital kidney (9). They may experience unconscious guilt and fear of punishment for theft and/or destructiveness (8). The adolescent's fear and guilt may enhance the inability to take reasonable risks. He or she must deal with fears of losing the "guardian of life" kidney and with the anxiety evoked by fantasies of harming the donor's kidney (11).

The recipient has particular difficulty in tolerating the experience and expression of hostility toward the self-sacrificing donor. Recipients do, however, characteristically experience ambivalence and hostile dependency toward the donor (6). Additional factors may stimulate hostile feelings toward the donor-parent. For example, hostility towards the donor is experienced when the kidney transplant has periods of poor function or when the kidney is actually-or threatens to be-rejected (8). Hostility may also be experienced because the parent, among others, remains free of the medical problems and cares that are still the burden of the recipient. At times, as previously mentioned, the parent-donor withdraws emotionally under the stress of anticipatory anxiety that the recipient will reject the kidney or die. In response, the adolescent may experience both hostility because of sensed abandonment and longing for closeness, and may respond by efforts-often regressive- to reestablish the tie.

In these ways, the recipient's experience of closeness, dependency, and guilt interfere with the adolescent's need and ability to achieve a sense of separateness and autonomy. For both the parent and child, then, the ability to accept the adolescent's autonomy and separation, to allow individual decision making that might incur risk, and to tolerate the experience of hostility, may be seriously compromised.

\section{Interference with Integration of Body Image and Development of Sexual Identity}

During adolescent development, there is increased awareness of the body, sexual maturation, an ac- ceptance of sexuality, and integration of a new body image. The adolescent who has received a transplant must deal with the normal changes in his or her body as well as the superimposed abnormal changes resulting from the transplant.

In these patients, the sense of body integrity is often already tenuous because of prior experience with dependence on hemodialysis (12). After transplantation, body damage fears are continuously stimulated, since the risk of transplant rejection or infection owing to immunosuppressive therapy is ever present. Just at the time when body cathexis is heightened, the recipient must deal with massive surgical scars. Body image is disturbed, at least initially, by a palpable "foreign-body" kidney (9). In addition, actual physical alterations result from the administration of corticosteroids, which produce distortions of face and body as well as other disfigurements such as stretch marks.

Peer group identification may be compromised because of the sense of being different, damaged, and because of the additional overt disfigurement produced by the corticosteroid treatment. Because of anxieties about being damaged and different, counterphobic reactions with risk-taking behavior or exaggerated assertiveness may occur (2). Conversely, the adolescent may withdraw from peers and activities that may highlight his or her vulnerability. Anxiety about causing harm to the appropriated parental kidney, as mentioned previously, can intensify overcautiousness.

For adolescents who are in the midst of solidifying their sexual identity, receiving a kidney of the parent of the opposite sex may be problematic in terms of fantasies about transformation to the sex of the donor (13). In addition, patients who receive a transplant from the opposite sex parent may experience some unconscious gratification of oedipal libidinal strivings (8). These factors may result in confusion and anxiety about sexual object choice.

\section{Case Presentation}

Excerpts from the brief treatment of a 19-year-old patient who had received a paternally donated kidney at age 16 are presented below. The material selected illustrates many of the psychological conflicts in such patients.

\section{Case History}

A patient had urologic surgery at age 2 years because of difficulty in voiding. At 14 years of age, he 
was found to be uremic. For the next 2 years he was chronically ill, although he continued to attend school despite several hospitalizations. When the patient was 16 years of age, it became clear that he had end-stage chronic pyelonephritis. $\mathrm{He}$ was placed on a hemodialysis program and evaluated for a transplant. There was no family or parental history of serious emotional disturbance, and no contraindication to the transplant was found. It was noted that the boy requested specifically that his father be the donor if possible. Soon thereafter, a bilateral nephrectomy was performed followed by a renal transplant, with the kidney being donated by the patient's father. The patient did well postoperatively. He was placed on high-dose steroids and immunosuppressive therapy.

Three years after the transplant procedure, it was noted that his weight had recently increased, probably because of an increased caloric intake. The patient's mother mentioned to the nephrologist that her son seemed to have developed a lack of interest in activities and in his environment. Psychiatric consultation was requested at that point.

Session 1. In the first session, the patient stated that his reason for coming was because his parents thought he was losing interest in everything, and perhaps his mother saw this as depression. His own view was that he didn't want to be overworked at his part-time job because he was afraid it would harm his kidney.

He related that the worst aspect of his job was his supervisor, a rigid man who watched over him and also told him that he was stupid. He described several confrontations with this man, in which the patient tried to "push him against the wall" by arguing and debating with him. The patient described difficulty falling asleep every night (after waking to urinate) because he kept thinking about the supervisor and had fantasies of beating him up.

Another problem for the patient was his mother's overprotectiveness, her wish to live his life, control his activities, and prevent him from being independent.

Session 2. In the second session, the patient elaborated on his symptoms. He mentioned difficulty in studying for school because of a "block," necessitating the dropping of a course. He described fatigue and lack of energy, felt he was not able to do much, and stayed at home.

When asked about his home and family, he began to speak of his father. He described him as someone really likable once you got to know him, someone whose friendship was hard to earn. He described him as both independent and dependent. The patient observed that his father felt independent when he knew how to do things; yet he was dependent because "if someone took Mom and me away he'd go nuts." He said his father did not leave him alone on weekends, since the father's schedule did not allow them much time together during the week. Further, his father did not show anger, controlled his temper, and usually would not say things twice, expecting the patient to do things right the first time. If the patient was at fault, he felt he was in the doghouse.

The patient then described his feelings about his father-donor and the transplant in displacement. "I had a coin collection when I was 15 . I dipped into it for money when I didn't have enough allowance. I didn't get spanked or anything. I broke his heart. He said I wasn't to do that anymore. That's all he said. Tears came to Dad's eyes because he helped me to get that coin collection going. It was a link between him and me. I started spending it, and he thought I was trying to break the link between him and me. The punishment is your knowing that it breaks his heart. It works on you.

"Now I' $m$ very careful about a coffee table that he made. I'm very careful not to mess it up. Everything he's done someone else has got. His brothers want his money and not him. I try to preserve whatever he has."

When the therapist noted that the transplant was also like a link between the two of them, the patient said he had not thought about it much, since his father had told him not to. One month after the transplant, he and his father had gone on a fishing trip together and talked about the transplant. His father told him that any father would have given his kidney. His father also said that even with the transplant he had 1 year to live, that he was man enough to know that, and that it should not bother him-he should just accept it. The therapist commented that it would be hard for anybody to do that, and wondered if perhaps his father expected a lot of him. To this the patient answered, "no."

When the therapist asked if the patient could tell more about how he felt about having his father's kidney, the patient responded with anger, saying "People try to get to you, and Dad said not to let them." The therapist pointed out that the patient had gotten angry at her. The patient acknowledged this was so, because she had gone against what his 
father said, and further: "You're going against Dad through me." When asked why it was so bad to go against Dad, the patient answered that he did not want to break his heart because of all the trouble that his father had gone through with the kidney transplant. He said the transplant had brought them closer together. When the therapist noted that instead of breaking his father's heart he broke his own, he tentatively agreed and then spoke about the many times he was angry at "them."

Session 3. In the third session, the patient stated that it was hard for him to get through school, and his parents were not helping much. He said his mother tried, but his father wanted to see them constantly on weekends, using his mother and himself as "a release valve," which put a strain on them. He told his mother that he had had to "drop them" in order to be alone and study. He had not told his father, and was assuming his father had figured it out.

He shifted to descriptions of his father as domineering and controlling, and his own resentment. He continued to describe other aspects of his father which made him angry, including the way his father initiated horseplay between them, often hitting him playfully. The patient could not overpower him with force. When asked if there was any other way he had the advantage over his father, the patient answered that he had good arguments. He then said: "I' $m$ worried about increasing my vocabulary and not being able to communicate." Later, the patient began to discuss his plans for the future, noting that he wished to go to a more distant college campus and earn enough money to live away from home.

Session 4. The patient looked less depressed when he walked into the office. He began by stating that he was feeling better, and things were going better. He had spoken with his parents, and they all had made a deal: they promised not to bring fattening foods into the house, and he agreed to go out more often. He remarked that when they had talked, he discovered that they had not wanted to talk to him about the problem because they did not want to "break my heart." He said he was happy that his parents were going out with each other now without expecting him to come along. They also no longer expected him to come home from the library within 10 minutes after he left it.

He turned then to the theme of fear of damage (retaliation) to his kidney, noting that there were relatives who got into horseplay with him, and he was very afraid that they would bump into his kidney and hurt it. He described his way of dealing with this, which was by sulking, since he did not want these relatives to feel insulted or angry.

At the end of the session the patient said he thought he could wait 2 or 3 weeks before the next appointment, and thought he could manage without weekly appointments.

Session 5. The patient began by noting that things were going better for him: he didn't eat nervously anymore, felt more calm, and could study better. He said: "The problem may be my parents and not me. I'm growing up and they can't take it. They don't like it. My brother did his growing up in the Army and they never had to see that. Both my. parents were brought up to think that the father is always right. They expect that one should always do what the father says. Since I've been in college, I know that the father is not always right."

Further material in this session indicated that the patient was resistant to further exploration, and at the end of the session he overtly said he did not think he needed any more sessions. Believing that sufficient work had been done to lift the depression, allow partial acceptance of hostile feelings, and promote the ability to separate, the therapist did not challenge the patient's wish to leave therapy and the therapist.

Follow-up after one year revealed that the patient was living in his own apartment, attending college, and doing well.

\section{Comment}

In the preceding excerpts, the following can be noted: links with the father and feelings of theft and guilt described in displacement (coin collection, coffee table); strivings for separation and independence, and fear of separation (being unable to communicate because of an increased vocabulary); hostility toward the father initially acceptable only as expressed in displacement (the rigid employer, the overprotective mother); and the partial acceptance of feelings of hostility. An acute stress in this case was the return home of the older brother from the armed services and his forthcoming marriage. The independence and ease of separation of this sibling made the patient's own dependent life all too clear by contrast.

The question of the usefulness of psychotherapy for adolescents on hemodialysis or posttransplanta- 
tion is an important one. Kaplan De-Nour has found psychotherapy with chronic dialysis patients to be extremely difficult, and doubts whether psychotherapy can be of great help to such adolescents (14). Drotar has suggested performing repeat evaluations of the child and family's psychological status throughout the stages of medical treatment in order to achieve early identification and prevention of severe emotional disturbance (3). In the author's view, long-term intensive psychotherapy for these adolescents is neither practicable nor desirable. For example, identifying such patients to be emotionally as well as physically abnormal may be imposing a great burden on those already troubled by their physical disabilities and differences. It is important, however, to maintain sensitivity to indications that interferences in development are becoming clinically significant. The identification of the periodic crises by nephrologists and treatment of the developmental logjams by psychotherapists with brief or intermediate therapy are crucial in assisting these adolescent patients.

\section{References}

1. Bernstein DM: After transplantation-The child's emotional reactions. Am J Psychiatry 127:1189-1193, 1971

2. Tisza VB, Dorsett P, Morse I: Psychological implications of renal transplantation. J Child Psychiatry 15:709-721, 1976

3. Drotar D: The treatment of a severe anxiety reaction in an adolescent boy following renal transplantation. J Am Acad Child Psychiatry 14:451-461, 1975
4. Poznanski EO, Miller E, Salguero C, Kelsh RC: Quality of life for long-term survivors of end-stage renal disease. JAMA 239:2343-2347, 1978

5. Zarinsky I: Psychological problems of kidney transplanted adolescents. Adolescence 10:101-107, 1975

6. Cramond WA: Renal transplantations-Experiences with recipients and donors. Sem Psychiatry 3:116132, 1971

7. Kemph JP: Renal failure, artificial kidney and kidney transplant. Am J Psychiatry 122:1270-1274, 1966

8. Kemph JP, Bermann EA, Coppolillo HP: Kidney transplant and shifts in family dynamics. Am J Psychiatry 125:1485-1490, 1969

9. Muslin HL: On acquiring a kidney. Am J Psychiatry 127:1185-1188, 1971

10. Basch $S:$ The intra-psychic integration of a new organ: A clinical study of kidney transplantation. Psychoanal Q 42:364-384, 1973

11. Kemph JP: Psychotherapy with donors and recipients of kidney transplants. Sem Psychiatry 3:145158,1971

12. Czaczkes JW, Kaplan De-Nour A: Chronic Hemodialysis as a Way of Life. Brunner/Mazel, New York, 1978

13. Cramond WA: Renal homotransplantation-Some observations on recipients and donors. Br J Psychiatry 113:1223-1230, 1967

14. Kaplan De-Nour A: Adolescents' adjustment to chronic hemodialysis. Am J Psychiatry 136:430-433, 1979

Direct reprint requests to:

Monica N. Starkman, M.D.

Department of Psychiatry

University of Michigan Medical Center

Ann Arbor, MI 48109 